\title{
CONSERVAÇÃO DE INIMIGOS NATURAIS (INSECTA) EM TOMATEIRO ORGÂNICO
}

\author{
P.H.B. Togni ${ }^{1 *}$, K.R. Cavalcante ${ }^{2}$, L.F. Langer ${ }^{3}$, C.S. Gravina ${ }^{1 * *}$, \\ M.A. de Medeiros ${ }^{4}$, C.S.S. Pires ${ }^{3}$, E.M.G. Fontes ${ }^{3}$, E.R. Sujii ${ }^{3}$
}

${ }^{1}$ Universidade de Brasília, Departamento de Ecologia, Instituto de Ciências Biológicas, CP 04457, CEP 70919970, Brasília, DF, Brasil. E-mail: pedrohbtogni@yahoo.com.br

\section{RESUMO}

\begin{abstract}
A adoção de práticas culturais como o consórcio de culturas e o tipo de irrigação podem beneficiar a comunidade de inimigos naturais no agroecossistema ao disponibilizar micro-habitas mais favoráveis e recursos alternativos, principalmente em períodos de baixa precipitação pluviométrica. O objetivo deste trabalho foi avaliar como o consórcio tomate + coentro e o tipo de irrigação (gotejamento e aspersão) podem beneficiar a comunidade de inimigos naturais no agroecossistema do tomateiro. O trabalho foi realizado no campo experimental da Embrapa Hortaliças, Gama, DF, de setembro a novembro de 2008. Os tomateiros foram plantados em monocultura ou consorciados com o coentro e irrigados por gotejamento e por aspersão (três repetições por tratamento), formando dois conjuntos de parcelas experimentais de acordo com o tipo de irrigação. A comunidade de inimigos naturais foi amostrada por observações diretas em 20 plantas de tomate por parcela e nas plantas de coentro sacudindo-se as plantas em cima de uma bandeja onde eram coletados os insetos. A abundância, riqueza e diversidade das espécies de inimigos naturais foram maiores nas parcelas cultivadas com coentro, independente do sistema de irrigação. Nas parcelas plantadas em monocultura foram encontradas mais espécies quando o tomateiro foi irrigado por aspersão. No entanto, a resposta de cada espécie de inimigo natural ou grupo de espécies foi distinta para o consórcio ou o tipo de irrigação. Portanto, em períodos de baixa precipitação, o consórcio tomate + coentro e a irrigação por aspersão podem favorecer a conservação de inimigos naturais no agroecossistema do tomateiro orgânico.
\end{abstract}

PALAVRAS-CHAVE: Controle biológico conservativo, Coriandrum sativum, Solanum lycopersicon, agricultura orgânica, agroecologia.

\begin{abstract}
CONSERVATIONOF NATURALENEMIES (INSECTA) INTHEORGANIC TOMATOCROP. The adoption of cultural practices such as companion plants and the kind of irrigation system can benefit the community of natural enemies in the agroecosystem due to the increase of more favorable microhabitats available and as a source of alternative resources, mainly in periods of low precipitation. This study evaluated how the tomato + coriander intercrop and the kind of irrigation (drip and sprinkler) could benefit the community of natural enemies in the tomato agroecosystem. This work was carried out in the experimental field of Embrapa Hortaliças, Gama, DF, from September to November 2008. The tomatoes were planted in monoculture or with coriander (companion plant) and irrigated by drip and sprinkler irrigation (three replicates per treatment), forming two groups of experimental plots according to the kind of irrigation. The community of natural enemies was sampled by the direct observation of specimens on 20 tomatoes plants per plot and in the treatments. Coriander plants were shaken over a plastic tray for collection of insects. The abundance, richness and diversity of natural enemies were higher in tomato + coriander plots, regardless of the irrigation system. We observed more species of natural enemies in tomato monoculture plots when it was irrigated by sprinkler irrigation. However, the cultural practices adopted had a different effect on each species or group of species. Therefore, in periods of low
\end{abstract}

\footnotetext{
${ }^{2}$ Centro Universitário de Brasília, Faculdade de Ciências da Saúde e Educação, Brasília, DF, Brasil.

${ }^{3}$ Embrapa Recursos Genéticos e Biotecnologia, Brasília, DF, Brasil.

${ }^{4}$ Embrapa Hortaliças, Laboratório de Entomologia, Gama, DF, Brasil.

*Programa de Pós-Graduação em Ecologia, Instituto de Ciências Biológicas, UnB.

**Programa de Pós-Graduação em Agronomia, UnB.
} 
precipitation, the tomato + coriander consortium associated with sprinkler irrigation can enhance the conservation of natural enemies in the organic tomato agroecosystem.

KEY WORDS: Conservation biological control, Coriandrum sativum, Solanum lycopersicon, organic crop, agroecology.

\section{INTRODUÇÃO}

Otomateé uma das principais hortaliças produzidas no Brasil, sendo cultivado em todas as regiões sob diferentes sistemas de manejo (IBGE, 2007). Embora a cultura seja susceptível à colonização por várias espécies de artrópodes-praga, principais limitantes de sua produção (Lopes FILHO, 1990), também existe uma grande diversidade de predadores e parasitoides associados. Em sistemas orgânicos de produção de tomate essas espécies podem ter efeitos diretos nas populações de herbívoros-praga, principalmente devido ao não uso de agrotóxicos e pelo aumento da complexidade do habitat para inimigos naturais através da consorciação de culturas (Hole et al., 2005).

Em cultivos orgânicos são adotadas práticas de manejocultural (e.g. consorciação deculturas, pousio emanejo do sistema de irrigação) que dificultam quea praga encontre a planta hospedeira e também favorecem o controle biológico natural de herbívoros-praga pelos seus inimigos naturais (LETOURNEAU; BOTHWELL, 2008). Na Califórnia, por exemplo, em sistemas orgânicos de produção de tomate, a comunidade de inimigos naturais é mais diversa do que em sistemas convencionais e a atuação destes pode compensar o uso de inseticidas para o controle de insetos-praga (Letourneau; Goldstein, 2001). No Brasil, apesar da grande diversidade de espécies que podem ser utilizadas em programas de controle biológico, essas ainda são pouco exploradas. Também são escassas as informações a cerca das práticas culturais (e.g. consórcio de culturas e manejo da irrigação) que podem favorecer a funcionalidade de espécies de inimigos naturais em agroecossistemas.

No agroecossistema do tomateiro, Togni $e t$ al. (2009), comparando a dinâmica populacional de B. tabaci em tomate plantado em monocultura e em consórcio com o coentro, verificaram que a abundância dos inimigos naturais foi próxima ao dobro no sistema orgânico em relação ao sistema convencional. Padrão semelhante foi observado por Medeiros (2007) que verificou maior riqueza e diversidade de espécies de inimigos naturais, como joaninhas e aranhas, em tomateiro consorciado com coentro e com botão-de-ouro, principalmente em sistemas orgânicos. Porém, ainda não são evidentes os mecanismos pelos quais as práticas culturais como consorciação de culturas e o tipo de irrigação podem influenciar na comunidade de inimigos naturais do tomateiro e favorecer o controle biológico natural de espécies-praga no tomateiro.

O objetivo deste trabalho foi avaliar o efeito do consórcio tomate + coentro e do tipo de irrigação (gotejamento e aspersão) na estrutura e composição da comunidade de inimigos naturais (Insecta) em sistema orgânico de produção de tomate e, assim, entender os mecanismos responsáveis pela abundância mais elevada dos inimigos naturais nos sistemas orgânicos. Provavelmente, o coentro é atrativo para predadores e parasitoides ao disponibilizar recursos alternativos, como pólen e néctar, para as espécies. $\mathrm{O}$ coentro apresenta floração intensa, flores expostase de fácil acesso que podem servir como fonte alternativa de alimento para os inimigos naturais (Mederroset al., 2009). A irrigação é um fator que também deve ser considerado, pois pode ter efeitos diretos negativos (e.g. desalojamento de ovos e imaturos) ou positivos (e.g. microclima mais favorável) na comunidade de inimigos naturais. Em períodos de baixa precipitação pluviométrica e temperaturas elevadas a irrigação por aspersão pode proporcionar um microclima mais favorável para os indivíduos, influenciando diretamente na comunidade de inimigos naturais.

\section{MATERIAIS E MÉTODOS}

Este trabalho foi realizado no campo experimental da Embrapa Hortaliças (CNPH) (15 56'S, $48^{\circ} 08^{\prime} \mathrm{W}$, altitude $997,6 \mathrm{~m}$ ), Gama, DF, de setembro a novembro de 2008. O campo experimental possui uma área total de 110 ha de latossolo vermelho escuro (EMBRAPA SolOs, 1999), sendo 18 ha destinados à área de pesquisa em produção orgânica de hortaliças (APPOH). Essa área é manejada de acordo com os princípios da agricultura orgânica desde 2001 e situa-se a, aproximadamente, $150 \mathrm{~m}$ da área de produção convencional e a $250 \mathrm{~m}$ de uma mata ciliar ao norte da área.

As parcelas experimentais foram formadas por plantas de tomate Solanum lycopersicon (Solanaceae) variedade Pollyana e coentro Coriandrum sativum (Apiaceae) variedade Verdão, em sistema de cultivo orgânico. Os tomateiros foram plantados em monocultivo ou consorciados com coentro sendo irrigados por gotejamento e por aspersão, compondo dois conjuntos de parcelas experimentais de acordo com o sistema de irrigação utilizado. Cada conjunto de parcelas experimentais media $1.377,6 \mathrm{~m}^{2}$ e eram distantes $20 \mathrm{~m}$ entre si. $\mathrm{O}$ experimento foi formado 
então pelos tratamentos: 1 . monocultivo de tomate irrigado por aspersão (AT), 2. consórcio tomate + coentro irrigado por aspersão (ATC), 3. monocultivo de tomateirrigado por gotejamento(GT), 4. consórcio tomate+coentro irrigado por gotejamento (GTC). Cada tratamento teve três repetições inteiramente casualizadas dentro de cada conjunto de parcelas. Cada parcela media $98,28 \mathrm{~m}^{2}$, espaçadas lateralmente $3,55 \mathrm{~m}$ e com uma rua central de $4 \mathrm{~m}$. Ao redor de cada conjunto de parcelas foram estabelecidas bordaduras de milho (Zea mays) e sorgo forrageiro (Sorghum bicolor) com a função de barreira de vento e para aumentar a diversidade de espécies no sistema produtivo.

Previamente ao plantio, foi realizada adubação verde com Crotalariajuncea e em seguida foi adubado com $200 \mathrm{~g} / \mathrm{m}$ linear de Termofosfato e $2 \mathrm{~kg} / \mathrm{m}$ linear de cama de matriz, seguindo o mesmo padrão utilizado em outros plantios na área experimental de produção orgânica. No início da primeira floração do tomateiro foi realizada adubação de cobertura com composto orgânico na base de cada tomateiro do experimento (SouZA; REZENDE, 2006). No gotejamento, as mangueiras dos gotejadores eram posicionadas nas laterais das plantas de tomate e nas bordaduras. $\mathrm{Na}$ aspersão a irrigação foi provida por nove aspersores dispostos entre as parcelas e distantes 8 $\mathrm{m}$ entre laterais e $18 \mathrm{~m}$ entre aspersores. Os turnos de rega foram estabelecidos a partir da leitura diária de tensiomêtros (um por parcela) (MAROUELLI, 2008).

Os tomateiros foram transplantados para $o$ campo na forma de mudas, com um par de folhas expandidas, em 26/7/2008 sendo uma muda por cova. Foi utilizado o sistema de fileiras duplas com espaçamento 0,55 m entre plantas, $0,8 \mathrm{~m}$ entre linhas simples e 1,6 m entre linhas duplas, totalizando nove linhas de plantio com 17 plantas por linha (153 plantas por parcela). Demais tratos culturais como desbaste e condução seguiram as recomendações técnicas de MAKISHIMA; MIRANDA (1992). Os tomateiros foram tutorados individualmente em sistema de varal, com uma planta por corda. Durante o ciclo da cultura foram realizadas duas aplicações de calda bordalesa, como prevenção a doenças causadas por fungos e bactérias (23/9/2008 e 8/10/2008), e duas aplicações de bioinseticida à base de Bacillus thuringienses (26/9/2008 e11/10/2008) para controle da traça-do-tomateiro.

A semeadura do coentro foi realizada no dia $28 / 7 / 2008$ entre os tomateiros nos dois sistemas de irrigação, não sendo aplicados tratos culturais específicos. Após 45 dias da semeadura o coentro foi colhido, sendo deixados de quatro a seis pés para florescer entre cada grupo de dois tomateiros. Após a colheita (10/9/2008) foi realizada a segunda semeadura do coentro entre os tomateiros. Estas plantas foram mantidas até o final do experimento com o objetivo de diponibilizar pólen e néctar para os inimigos naturais (MEDEIROs, 2007).

Duas semanas antes da colheita do coentro foram iniciadas as coletas de predadores e parasitoides nos tratamentos. Foram amostradas aleatoriamente 20 plantas de tomate por parcela em busca de inimigos naturais (predadores e parasitoides) nas plantas. Os predadores e parasitoides foram coletados com aspirador entomológico elevados aolaboratório para montagem e identificação. Para a amostragem dos inimigos naturais presentes no coentro foi colocada uma bandeja plástica ( $52 \mathrm{~cm} \times 31 \mathrm{~cm} \mathrm{e} 9 \mathrm{~cm}$ dealtura), abaixo das plantas e estas foram sacudidas vigorosamente. Os indivíduos que caíram sobre a bandeja foram coletados com um aspirador entomológico, sendo registrada a abundância de cada espécie.

A similaridade entre as comunidades deinimigos naturais coletados nos tratamentos foi calculada pelo índice de similaridade de Jaccard (KREBS, 1999). A diversidade de espécies entre os tratamentos foi calculada pelo índice de Shannon-Wiener para as médias de inimigos naturais por semana em cada tratamento. Este índice permitiu a comparação estatística entre diferentes amostras por uma modificação no teste $t$ de Student (HAMMER et al., 2001; ZHAR 1999). A dominância de cada espécie em relação à abundância total de espécies foi calculada pelo método de similaridade das porcentagens SIMPER (CLARKE, 1993). Em seguida, foi testado se a abundância dos indivíduos em cada tratamento (monocultivo de tomate e consórcio tomate + coentro irrigados por gotejamento ou por aspersão) ajustava-se ao modelo de distribuição log-normal para verificar como cada espécie responde aos tratamentos (KREBS, 1999). A influência do consórcio com coentro e do manejo da irrigação na estrutura e composição da comunidade de inimigos naturais coletados foram avaliados pelo Escalonamento Multidimensional Não-Métrico (NMDS) das variáveis analisadas (abundância, riqueza e diversidade de espécies) ao longo do período de amostragem. A similaridade entre os autovalores do algoritmo das variáveis foi calculada pelo índice de similaridade de Bray-Curtis, para verificar a similaridade das comunidades de inimigos naturais entre os tratamentos (CLARKE, 1993; HAMMER et al., 2001).

\section{RESULTADOS E DISCUSSÃO}

Foi observada maior abundância, riqueza, número de espécies por planta e maior diversidade nos tratamentos com coentro em relação ao monocultivo de tomate, independente do sistema de irrigação (Tabela 1). LANGELLOTO; DeNNO (2004), utilizando técnicas de meta-análise, demonstraram que o aumento da complexidade do habitat pela consorciação de 
culturas aumenta a abundância e diversidade de espécies em relação a habitats homogêneos como as monoculturas. As principais causas desse aumento na abundância e diversidade de inimigos naturais são principalmente pela maior disponibilidade de refúgios contra predação intraguilda e acesso a recursos alimentares alternativos (presas, pólen ou néctar) nos habitats mais complexos (AltiERI, 1999; Colley; Luna, 2000; McCann, 2000). As condições microclimáticas proporcionadas pela irrigação por aspersão em períodos secos, como o período de realização deste trabalho, devido ao molhamento do dossel das plantas, podem ser mais favoráveis para as espécies em comparação ao gotejamento próximo às raízes. Isso explica a maior abundância, número de espécies e maior diversidade verificada no monocultivo de tomate irrigado por aspersão em relação ao seu equivalente no gotejamento, apesar da maior riqueza de espécies no gotejamento (Tabela 1).

A partir da quarta semana de amostragem foi observado um aumento na abundância dos inimigos naturais amostrados, o que coincidiu com o período em que mais de $90 \%$ das plantas de coentro estavam floridas. Foi verificada uma alta similaridade qualitativa (Índice de Jaccard $=0,78954$ ) entre as espécies de inimigos naturais encontradas no coentro e no tomateiro. Isso indica que as espécies que utilizam de alguma forma as plantas de coentro também utilizam o tomateiro durante seu desenvolvimento. Provavelmente, o coentro ao florescer disponibiliza recurso alternativo para os inimigos naturais (presas alternativas, pólen enéctar). A maior disponibilidade de recursos alimentares pode aumentar as taxas de assimilação de $\mathrm{C}$ e $\mathrm{N}$ pelos indivíduos (PAтT et al., 2003) e, assim, aumentar o sucesso reprodutivo de predadores como Chrysoperla externa (Neuroptera: Chrysopidae), pela complementação da dieta com néctar e pólen(Venzonet al., 2006). Por isso, o coentro foi considerado atrativo para diversas espécies de inimigos naturais avaliados.

Foram identificadas no total sete ordens de inimigos naturais (predadores e parasitoides) da classe Insecta. A ordem Hymenoptera foi dividida entre vespas predadoras e parasitoides. Dentre os predadores em geral, dez espécies foram da ordem Coleoptera, quatro Hemiptera, dois Diptera e dois Hymenoptera, e uma de Dermaptera, Mantodea e Neuroptera (Tabela 2). Na ordem Hymenoptera foram identificadas 11 famílias de parasitoides: Braconidae, Scelionidae, Eulophidae, Pteromalidae, Megaspilidae, Bethylidae, Eupelmidae, Diapriidae, Phigilidae, Ichneumonidae e Mymaridae.

As espécies com índices de importância mais elevados para o sistema foram, Hippodamia convergens (Coleoptera: Coccinellidae), Allograpta sp. (Diptera: Syrphidae), Eriopis connexa (Coleoptera: Coccinellidae), Condylostylus sp. (Diptera: Dolichopodidae) e parasitoides, respectivamente (Tabela 2). Todas essas espécies possuem hábito alimentar polífago, podendo ser responsáveis pelo controle populacional de diferentes herbívoros-praga no agroecossistema (OBRYCKI; KRING, 1998).

A estrutura das comunidades foi semelhante entre os tratamentos se ajustando a um modelo de distribuição do tipo Log-normal (KREBS, 1999) com dominância de poucas espécies muito abundantes (Fig. 1). Apesar de apresentarem estrutura semelhante, a composição de espécies da comunidade e as densidade destas variaram de acordo com o tipo de manejo (irrigação e consórcio com o coentro), sendo menos abundantes no monocultivo de tomate irrigado por gotejamento. Oconjunto de inimigos naturais encontradoséformado dequatrocomunidades com estruturas semelhantes, porém com composição e abundância de espécies distintas (Fig. 1).

Tabela 1 - Número de espécies por planta (média \pm desvio padrão), abundância e diversidade de inimigos naturais (Shannon-Wiener) coletados em plantas de tomate e de coentro nos tratamentos monocultivo de tomate irrigado por aspersão (AT), consórcio tomate + coentro irrigado por aspersão (ATC), monocultivo de tomate irrigado por gotejamento (GT) e consórcio tomate + coentro irrigado por gotejamento (GTC) em sistema orgânico de produção do campo experimental da Embrapa Hortaliças, Gama, DF, 2008.

\begin{tabular}{lcccc}
\hline Tratamento & Abundância $^{1}$ & Espécies por planta $^{2}$ & Riqueza & ${\text { Diversidade }(\mathrm{H})^{3}}^{\text {AT }}$ \\
\hline AT, $\pm 8,8 \mathrm{a}$ & $3,54 \pm 1,29 \mathrm{a}$ & 11 & 1,521 \\
ATC & $31,96 \pm 16,13 \mathrm{~b}$ & $6,75 \pm 2,47 \mathrm{~b}$ & 17 & 1,977 \\
GT & $7,79 \pm 7,18 \mathrm{c}$ & $3,04 \pm 1,65 \mathrm{c}$ & 14 & 1,922 \\
GTC & $27,38 \pm 17,09 \mathrm{~b}$ & $6,42 \pm 2,72 \mathrm{~b}$ & 17 & 2,042 \\
\hline
\end{tabular}

Médias seguidas das mesmas letras na coluna não diferiram significativamente $(\mathrm{P}>0,05)$ pelo teste de Dunn.

${ }^{1}$ Kruskal-Wallis $\mathrm{H}_{3,1}=34,69, \mathrm{P}<0,001$;

${ }^{2}$ Kruskal-Wallis $\mathrm{H}_{3,1}^{3}=37,79, \mathrm{P}<0,001$;

${ }^{3}$ AT $x$ ATC $\mathrm{t}=-6,9806, \mathrm{P}<0,0001 ; \mathrm{GT} \times \mathrm{GTC} \mathrm{t}=-3,1762, \mathrm{P}=0,001$. 
Tabela 2 - Ocorrência de inimigos naturais nos tratamentos monocultivo de tomate irrigado por aspersão (AT), consórcio tomate + coentro irrigado por aspersão (ATC), monocultivo de tomate irrigado por gotejamento (GT) e consórcio tomate + coentro irrigados por gotejamento (GTC) e importância relativa da abundância de cada espécie para o agroecossistema calculado a partir da porcentagem de similaridade entre os tratamentos (SIMPER). Campo experimental da Embrapa Hortaliças, Gama, DF, 2008.

\begin{tabular}{lllllll}
\hline \multirow{2}{*}{ Categoria taxonômica } & \multicolumn{4}{c}{ Tratamento } & Importância relativa \\
\cline { 2 - 5 } & AT & ATC & GT & GTC & \\
\hline
\end{tabular}

Coleoptera

Coccinellidae

Cycloneda sanguinea

Coleomegila maculata

Eriopis connexa

Harmonia axyridis

Hippodamia convergens

Hyperaspis festiva

Nephaspis sp.

Olla v-nigrum

Psyllobora sp.

Scymnus sp.

Hemiptera

Lygaeidae

Geocoris sp.

Anthocoridae

Orius sp.

Pentatomidae

Podisus sp.

Reduviidae

Zellus sp.

Diptera

Dolichopodidae

Condylostylus sp.

144

146

28

17

Syrphidae

Allograpta sp.

44

233

34

72

Hymenoptera

Vespidae (vespas predadoras)

Outros himenópteros

Parasitoides

Neuroptera

Chrysopidae

Chrysoperla externa

1

11

36

7

7

108

156

72

53

Mantodea

Mantidae sp.1

0

Dermaptera

\section{Forficulidae}

Doru luteipes

Total
9,995

1,262

4,606

2,073

0,04325

8,579

0,04325

12,26

0,2294

0,5692

0,04872

0,1429

1,475

1,073

0,3934

0,04764

0,09528

1,289

0,225

$\begin{array}{lll}348 & 768 & 187\end{array}$

187

0

0,5673 
Os coccinelídeos foram mais abundantes no consórcio tomate + coentro, independente do sistema de irrigação (Tabela 2 e Fig. 1). Para essas espécies o coentro pode servir como recurso alternativo de várias formas (ver detalhes em FiEDLER; LANDIS, 2007). O coentro de forma geral não apresenta grandes problemas com pragas, porém pode ser hospedeiro para pulgões que servem como presa alternativa às normalmente encontradas no tomateiro. Por isso, ao longo do experimento foram observadas pupas e ovos de coccinelídeos nessas plantas. Também foram observados indivíduos de Coccinellidae (Cycloneda sanguinea, Eriopis connexa, Hippodamia convergens e Scymnus sp.) se alimentando das inflorescências do coentro, da mesma forma que observado por RESENDE (2008) em couve consorciada com coentro em sistema orgânico. Por isso, para as espécies coletadas de Coccinellidae, o coentro serviu como fonte alternativa de alimentação e oviposição, confirmando o observado por MedeIros et al. (2009) que encontraram pólen de diversas famílias botânicas no aparelho digestivo dos predadores $H$. convergens e $C$. externa, sendo a família Apiaceae uma das mais representativas, principalmente para $H$. convergens.

Para Condylostylus sp. (Diptera: Dolichopodidae), que pode voar ativamente por longas distâncias, o manejo da irrigação foi mais relevante que o consórcio com o coentro. Considerando que o experimento foi conduzido no período da seca no Distrito Federal (altas temperatura e baixa precipitação pluviométrica) é provável que este tipo de irrigação crie microclimas mais favoráveis para Condylostylus sp. e outras espécies de inimigos naturais com hábito e comportamento semelhantes. Para os parasitoides o mesmo padrão é observado. Porém, estes podem utilizar o néctar como complemento alimentar para que sejam mais eficientes na localização e parasitismo de seus hospedeiros (BIANCHI; WACKERS, 2008). Já Allograpta sp. pode aproveitar o pólen e néctar disponibilizado pelo coentro como alimento (Colley; Luna, 2000). Para espécies de sirfídeos de hábito forrageador ativo como Allograpta exotica, a arquitetura, facilidade de acesso e disponibilidade de néctar e pólen nas flores é um fator determinante para sua atração (Morales; KöHLE, 2008). Os Syrphidae parecem ser afetados aditivamente pelo microclima da irrigação por aspersão e pela grande quantidade de flores do coentro. A disponibilidade, a quantidade e qualidade dos recursos florais têm influencia na atração desses dípteros, uma vez que são pequenos visitantes florais (ARRUDA et al., 1998). Nesse sentido, o coentro apresenta inflorescências abundantes e bem expostas facilitando o acesso de diferentes espécies ao recurso.

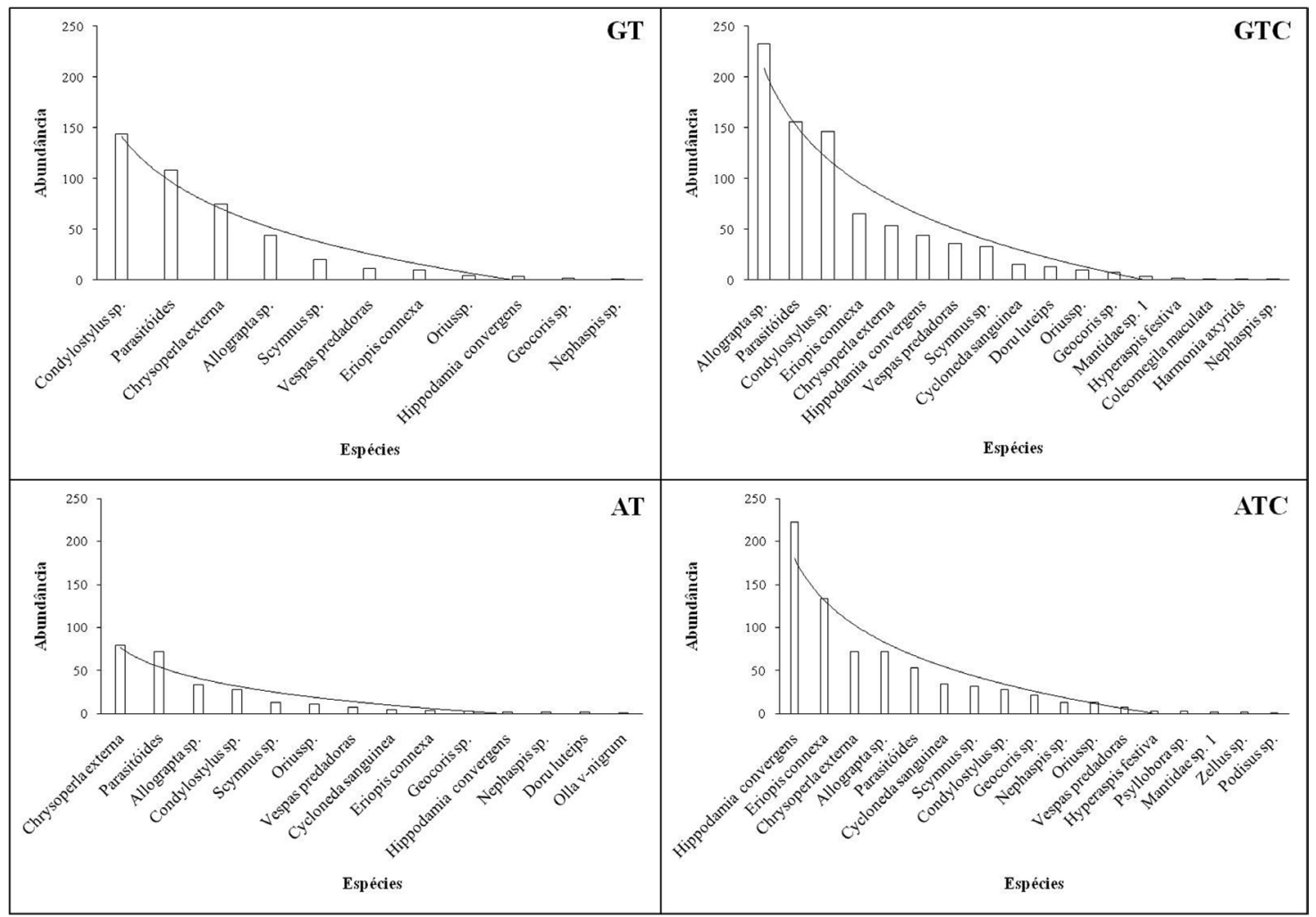

Fig. 1 - Estrutura e composição da comunidade de inimigos naturais coletados nos tratamentos monocultivo de tomate irrigado por aspersão (AT), consórcio tomate + coentro irrigado por aspersão (ATC), monocultivo de tomate irrigado por gotejamento (GT) e consórcio tomate + coentro irrigado por gotejamento em sistema orgânico de produção no campo experimental da Embrapa Hortaliças, Gama, DF, 2008. 


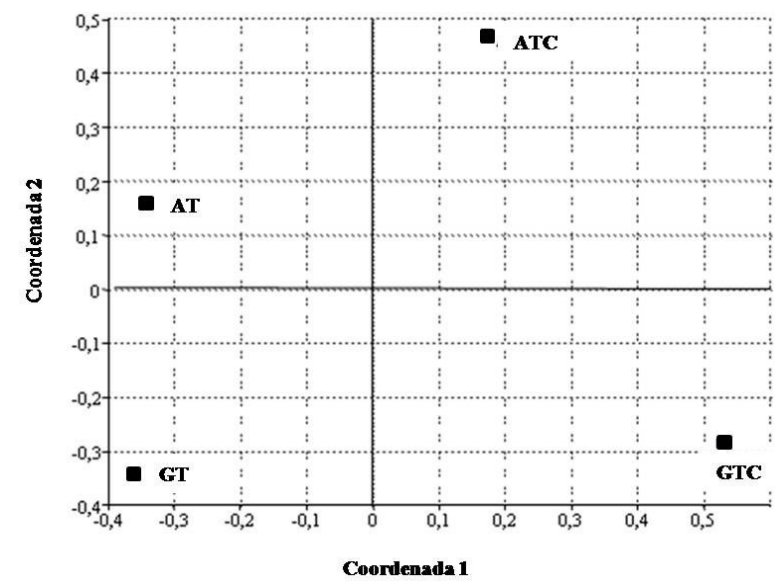

Fig. 2 - Ordenamento das comunidades de inimigos na-turais que ocorreram em parcelas de tomate em monocultivo e consorciado com coentro e sob diferentes tipos de irrigação (gotejamento e aspersão) utilizando a técnica de Escalonamento Multidimensional Não-Métrico (NMDS). Tratamentos: monocultivo de tomate irrigado por aspersão (AT), consórcio tomate + coentro irrigado por aspersão (ATC), monocultivo de tomate irrigado por gotejamento (GT) e consórcio tomate + coentro irrigado por gotejamento (GTC). Embrapa Hortaliças, Gama , DF, 2008. Similaridade na estrutura da comunidade entre os tratamentos realizada pelo índice de Bray-Curtis. Shepard plot stress $<0,01$.

As diferenças na composição das comunidades de inimigos naturais e os tipos de resposta de cada espécie às práticas de manejo adotadas resultaram em quatro agrupamentos distintos em cada tratamento, em função das práticas culturais adotadas em cada tratamento (Fig. 2). A composição das espécies também é influenciada pelo tipo de irrigação, uma vez que nos tratamentos consorciados esta difere quanto ao manejo da irrigação. Nos tratamentos monocultivo de tomate essas comunidades foram ordenadas mais próximas umas das outras e mais distantes das comunidades dos tratamentos consorciados (Fig. 2). Essas diferenças se devem à resposta de cada espécie a cada um dos fatores avaliados (irrigação e consórcio com coentro). Outros autores também observaram mudanças na composição da comunidade de inimigos naturais em função das práticas culturais adotadas por cada produtor, onde o manejo da irrigação e o consórcio de plantas afetam de modo diferenciado cada espécie no agroecossistema (LetourneAU; GoldSTEIN, 2001; THOMSON, 2006).

\section{CONCLUSÕES}

- O consórcio tomate+coentro favoreceu a conservação de inimigos naturais no agroecossistema do tomateiro, independente do sistema de irrigação, havendo indicações de que o coentro é atrativo para diferentes espécies, principalmente para os Coccinellidae e Allograpta sp.

- A irrigação por aspersão em tomateiro plantado em monocultura favorece a comunidade de inimigos naturais em comparação ao gotejamento, em períodos de baixa precipitação pluviométrica.

- Cada espécie ou grupo de espécies responde de forma diferenciada às práticas de manejo adotadas (irrigação e consórcio com o coentro).

\section{AGRADECIMENTOS}

À CAPES pela disponibilização da bolsa de estudos do primeiro autor. À Fundação de Apoio à Pesquisa do Distrito Federal - FAPDF, Conselho Nacional de Desenvolvimento Científico e Tecnológico - CNPq e Centro de Desenvolvimento da Agricultura Orgânica do Distrito Federal - CDTorg - DF pelo suporte financeiro ao projeto. À Embrapa Recursos Genéticos e Biotecnologia e Embrapa Hortaliças pela disponibilização da infraestrutura. Ao Dr. Raúl A. Laumann (Embrapa Cenargen) pela identificação das famílias de parasitoides. Ao M.Sc. Ronaldo Setti, Josimar Couto e equipe orgânica, Dr. Waldir A. Marouelli e Dr. Francisco V. Resende da Embrapa Hortaliças pelo auxílio na condução do experimento.

\section{REFERÊNCIAS}

ALTIERI, M.A. The ecological role of biodiversity in agroecosystems. Agriculture, Ecosystems \& Environment, v.74, p.19-31, 1999.

ARRUDA, V.L.V.; SAZIMA. M.; PIEDRABUENA, A.E. Padrões diários de atividade de sirfideos (Diptera, Syrphidae) em flores. Revista Brasileira de Entomologia, v.41, p.141-150, 1998.

BIANCHI, F.J.J.A.; WACKERS, F.L. Effects of flower attractiveness and nectar availability in field margins on biological control by parasitoids. Biological Control, v.46, p.400-408, 2008.

CLARKE, K.R. Non-parametric multivariate analyses of changes in community structure. Austral Ecology, v.18, p.117-143, 1993.

COLLEY, M.R.; LUNA, J.M. Relative attractiveness of potential beneficial insectary plants to aphidophagous hoverflies (Diptera: Syrphidae). Environmental Entomology, v.29, n.5, p.1054-1059, 2000.

EMBRAPA SOLOS. Centro Nacional de Pesquisa de Solos. Sistema brasileiro de classificação de solos. Rio de Janeiro: Embrapa Solos, 1999. 412p. 
FIEDLER, A.K.; LANDIS, D.A. Attractiveness of Michigan native plants to arthropod natural enemies and herbivores. Environmental Entomology, v.36, p.751-765, 2007.

HAMMER, O.; HARPER, D.A.T.; RYAN, P.D. Paleontological statistics software package for education and data analyses. Paleontologia Electronica, v.4, n.1, p.1-9, 2001. Disponível em: <http:/ / folk.uio.no/ohammer/ past/>. Acesso em: 5 nov. 2008.

HOLE, D.G.; PERKINGS, A.J.; WILSON, J.D.; ALEXANDER, I.H.; GRICE, P.V.; EVANS, A.D. Does organic farming benefit the biodiversity? Biological Conservation, v.122, n.1, p.113-130, 2005.

IBGE - Instituto Brasileiro de Geografia e Estatística. Levantamento sistemático da produção agrícola. 2007. Disponível em: <http:/ / www.ibge.gov.br/home/ estatistica>. Acessado em: 10 out. 2008.

KREBS, C.J. Ecological methodology. 2.ed. Califórnia: Addison-Welsey, 1999. 620 p.

LANGELLOTTO, G.A.; DENNO, R.F. Responses of invertebrate natural enemies to complex-structured habitats: a meta-analytical synthesis. Oecologia, v.139, p.1-10, 2004.

LETOURNEAU, D.K.; BOTHWELL, S.G. Comparison of organic and conventional farms: challenging ecologists tom make biodiversity functional. Frontiers in Ecology and the Environment, v.6, p.430-438, 2008.

LETOURNEAU, D.K.; GOLDSTEIN, B. Pest damage and arthropod community structure in organic vs. conventional tomato production in California. Journal of Apllied Ecology, v.38, p.557-570, 2001.

LOPES FILHO, F. Tomate industrial no submédio São Francisco e as pragas que limitam sua produção. Pesquisa Agropecuária Brasileira, v.25, p.283-288, 1990.

MAKISHIMA, N.; MIRANDA, J.E.C. Cultivo do tomate (Lycopersicon esculetum Mill.). Brasília: Embrapa Hortaliças, 1992. 22p. (Instruções Técnicas da Embrapa Hortaliças 11).

MAROUELLI, W.A. Tensiometros para o controle de irrigação em hortaliças. Brasília: Embrapa Hortaliças, 2008. 15p. (Circular Técnica da Embrapa Hortaliças 57). Disponível em: $<$ http://www.cnph.embrapa.br/paginas/publicacoes/publicacoes.htm>. Acesso em: 14 jul. 2008.

McCANN, K.S. The diversity-stability debate. Nature, v.405, p.228-233, 2000.

MEDEIROS, M.A. Papel da Biodiversidade no manejo da traça-do-tomateiro Tuta absoluta (Meyrick, 1971) (Lepidoptera: Gelechiidae). 2007. 145f. Tese (Doutorado em Ecologia - Área de Ecologia) - Instituto de Biologia, Universidade de Brasília, Brasília, DF, 2007.
MEDEIROS, M.A.; RIBEIRO, P.A.; MORAIS, H.C.; CASTELO-BRANCO, M.; SUJII, E.R.; SALGADOLABORIAU, M.L. Indentification of plant families associated with the predators Chrysoperla externa (Hagen) (Neuroptera: Chrysopidae) and Hippodamia convergens (Guérin-Menéville) (Coleoptera: Coccinellidae) using pollen grain as natural marker. Brazilian Journal of Biology, v.70, n.2, 2009 .

MORALES, M.N.; KÖHLE, A. comunidade de Syrphidae (Diptera): diversidade e preferências florais no cinturão verde (Santa Cruz do Sul, RS, Brasil). Revista Brasileira de Entomologia, v.52, p.41-49, 2008.

OBRYCKI, J.J.; KRING, T.J. Predaceous Coccinellidae in biological control. Annual Review of Entomology, v.43, p.295-321, 1998.

PATT, J.M.; WAINRIGHT, S.C.; HAMILTON, G.C.; WHITTINGHILL, D.; BOSLEY, K.; DIETRICK, J.; LASHOMB, J.H. Assimilation of carbon and nitrogen from pollen and nectar by a predaceous larva and its effects on growth and development. Ecological Entomology, v.28, n.2, p.717-728, 2003.

RESENDE, A.L.S. Comunidade de joaninhas (Coleoptera: Coccinellidae) e aspectos fitotécnicos da couve (Brassica oleraceae var. acephala) em consórcio com o coentro (Coriandrum sativum), sob manejo orgânico. 2008. 85f. Dissertação (Mestrado em Fitotecnia - Área de Fitotecnia com ênfase em Agroecologia) - Instituto de Agronomia, Universidade Federal Rural do Rio de Janeiro, Seropédica, 2008.

SOUZA, J.L.; RESENDE, P. Manual de horticultura orgânica. 2.ed. Viçosa: Aprenda Fácil Editora, 2006. 843p.

THOMSON, L.J. Influence of reduced irrigation on beneficial invertebrates in vineyards. Australian Journal of Experimental Agriculture, v.46, n.10, p.1389-1395, 2006.

TOGNI, P.H.B.; FRIZZAS, M.R.; MEDEIROS, M.A.; NAKASU, E.Y.T.; PIRES, C.S.S.; SUJII, E.R.S. Dinâmica populacional de Bemisia tabaci biótipo b em tomate monocultivo e consorciado com coentro sob cultivo orgânico e convencional. Horticultura Brasileira, v.27, n.2, p.183-188, 2009.

VENZON, M.; ROSADO, M.C.; EUZÉBIO, D.E.; SOUZA, B.; SCHROEREDER, J.H. Suitability of leguminous cover crop pollens as food source for the Green lacewing Chrysoperla externa (Hagen) (Neuroptera: Chrysopidae). Neotropical Entomology,v.35, n.3, p.371-376, 2006.

ZHAR, J.H. Biostatistical analysis. New Jersey: Prentice Hall, 1999. 663p.

Recebido em 16/6/09

Aceito em 28/10/10 